\title{
Improved Gas Separation of PEBAX-CSWCNTs Mixed Matrix Membranes
}

\author{
Pouria Abbasszadeh Gamali ${ }^{1,2}$, Mohammadreza Rahmani ${ }^{1,3}$, Abbass Kazemi ${ }^{1, *}$ and \\ Mahnaz Pourkhalii ${ }^{1}$
}

${ }^{1}$ Nanotechnology and Carbon Research Center, Research Institute of Petroleum Industry (RIPI), Tehran, Iran

${ }^{2}$ Chemistry \& Chemical Engineering Research Center of Iran, Tehran, Iran

${ }^{3}$ Department of Chemical Engineering, Babol Noshirvani University of Technology, Babol, Iran

\begin{abstract}
In the present study, mixed matrix membranes (MMMs) were prepared using PEBAX ${ }^{\circledR} 3000$ as polymer matrix and single-wall carbon nanotubes (SWCNTs) functionalized with carboxyl groups as nanofillers. The effects of the nanofillers on separation of $\mathrm{CO}_{2} / \mathrm{N}_{2}$ and $\mathrm{CO}_{2} / \mathrm{CH}_{4}$ were investigated. The pristine PEBAX membrane indicated gas selectivity values of 23 and 13 for $\mathrm{CO}_{2} / \mathrm{N}_{2}$ and $\mathrm{CO}_{2} / \mathrm{CH}_{4}$, respectively. However selectivity of the modified membrane for gas pairs of $\mathrm{CO}_{2} / \mathrm{N}_{2}$ and $\mathrm{CO}_{2} / \mathrm{CH}_{4}$ improved to the values of 106.4 and 31.3 , respectively. In other words, selectivity of modified membranes compared to those of unmodified ones enhanced greatly. The dramatic increase in gas selectivity of the mixed matrix membranes can be attributed to the polar groups of caboxyl-functionalized single-wall carbon nanotubes (CSWCNTs). While $\mathrm{CO}_{2}$ permeability of MMMs increaesd, permeability of nonpolar gases $\left(\mathrm{N}_{2}\right.$ and $\left.\mathrm{CH}_{4}\right)$ decreased. FTIR spectra depicted that there were inter/intramolecular forces between ether and amide groups of the polymer chains. For PEBAX membrane filled with $10 \mathrm{wt} \%$ CSWCNTs, the peaks of $\mathrm{C}-\mathrm{O}-\mathrm{C} \cdot \mathrm{N}-\mathrm{H}$, and $\mathrm{H}-\mathrm{N}-\mathrm{C}=\mathrm{O}$ functional groups shifted to lower values due to the formation of hydrogen bonds between polar carboxyl groups of CSWCNTs and amide/ether groups of PEBAX copolymer. Relative crystallinity values of the membranes with various CSWCNTs content were calculated using $\Delta \mathrm{H}_{\mathrm{f}}$ data obtained from DSC measurements. Results demonstared that the rise in content of CSWCNTs brought about the decrement in crystallinity values of polyamide segments. The morphology of the membrane containing $10 \mathrm{wt} \%$ CSWCNTs was also investigated emplying AFM images, and a suitable compatability and adhere between PEBAX and CSWCNTs was last confirmed.
\end{abstract}

Keywords: Mixed matrix membranes (MMMs), Poly(ether-block-amide), Nanofillers, Permselectivity, Gas separation.

\section{INTRODUCTION}

In recent years, mixed matrix membranes (MMMs) have been immensely studied because of their capabilities to be utilized in a wide range of applications in gas separation technology. In general, polymer membranes are economically of more interest than other types of membranes because of their easily processability [1-7]. Cellulose acetate, Polyimides, Polyethylene glycol, to name just a few, used to apply in order to prepare membranes [8]. What is more, enhanced permselectivity of membranes can be achieved by chemical modification. Tailored-functional membranes can be made using nanomaterials incorporated into the polymer matrix, leading to hybrid membranes preparation with improved chemical and physical properties. In most cases, MMMs indicate both higher gas permeabilities and better gas selectivities compared to those of pristine membranes [9-12].

Poly (ether block amide), commercially known as PEBAX, is made up of two various segments including, linear chaines of rigid polyamide (PA) and flexible

*Address correspondence to this author at the Nanotechnology and Carbon Research Center, Research Institute of Petroleum Industry (RIPI), Tehran, Iran; Tel: 009821 48255404; Fax: 009821 44739696; E-mail: kazemiab@ripi.ir polyether (PE). High mobility of PE segments makes permeability of gases through PEBAX way easier. The rubbery $\mathrm{PE}$ segments possess a glass transition temparature below room temperature and thus it makes polymer chains flexible. PA segments, however, can be crystallized at glass transition temperature above room temperature, so proper thermal and mechanial strength are provided for PEBAX membranes. It is worth noting that gases mainly transport through the amorphous PE phase. The compatibility of PEBAX and inorganic nanofillers has positive effects on mechanical and thermal properties of MMMs. The higher gas permeability and permselectivity were resulted from the hybrid membranes. The improved permeation properties can be attributed to the interactions between $\mathrm{CO}_{2}$ molecules and $\mathrm{SiO}_{2}$ nanoparticles within the polymer matrix. Moreover, additional sorption sites were provided in PE blocks of PEBAX at organic-inorganic interfaces. In order to produce MMMs, solution casting is a simple procedure whereby inorganic nanofillers can be dispersed whitin a polymer solution. Once solvent evaporates, MMMs will be formed on the bottom of petri dish. The high permeability and selectivity of PEBAX membranes can be attributed to the special affinity between polarizable gases and PE 
segments in PEBAX chains. Kim et al. employed a solgel process for preparation of hybrid membrane of PEBAX/silica [13-16].

The effect of inorganic fillers on properties of MMMs is associated with their surface chemistry, chemical structure and size of particles. In general, inorganic fillers are divided into two distinct groups, porous and nonporous types. Each of the filler types has various effects on properties of MMMs. Porous fillers tend to act as a molecular sieving agent and separate gas components by their size. In fact, incorporation of porous fillers into polymer matrix raises permeability of desired gas component through membrane. Adding porous fillers can also increase selectivity of MMMs. As a result, the advantages of polymeric and inorganic fillers are combined by preparation of MMMs. Apart from molecular sieving, adding fillers possessing large pore size to polymer matrix can induce selective surface flow. It can be concluded that small and polar component $\left(\mathrm{CO}_{2}\right)$ can be adsorbed and diffused through the pores comfortably compared to the other components $\left(\mathrm{N}_{2}\right.$ and $\left.\mathrm{CH}_{4}\right)$. Therefore, $\mathrm{N}_{2}$ and $\mathrm{CH}_{4}$ permeate more slowly than $\mathrm{CO}_{2}$. Generally, the ways that nanofillers affect gas separation performance of MMMs can be gategorozed into by four various models, including Maxwell model, Free-volume increase, Solubility increase, and Nanogap hypothesis, which was thoroughly explianed in our previous study [1].

The primary focus of this study was to prepare super-permeable MMMs. Hence, PEBAX ${ }^{\circledR} 3000$ and CSWCNTs were employed as polymer matrix and nanofillers, respectively, to fabricate composite membranes. The impact of polar nanofillers, playing a big part in rising gas selectivity, on both permeabilities of $\mathrm{CO}_{2}, \mathrm{~N}_{2}$, and $\mathrm{CH}_{4}$ and selectivitis of $\mathrm{CO}_{2} / \mathrm{N}_{2}$ and $\mathrm{CO}_{2} / \mathrm{CH}_{4}$ were examined. The enhanced $\mathrm{CO}_{2} / \mathrm{N}_{2}$ and $\mathrm{CO}_{2} / \mathrm{CH}_{4}$ selectivities were achieved which is a new record for PEBAX ${ }^{\circledR} 3000$ membranes.

\section{EXPERIMENTAL}

\subsection{Materials and Membranes Preparation}

PEBAX ${ }^{\circledR} 3000$ with a chemical structure as shown in Figure 1 and CSWCNTs were purchased from Arkema and Nanocy, respectively. N,N'-dimethyl-acetamide (DMAc) as solvent was provided from Fluka and used as received. Pure gases were dedicated by research institute of petroleum industry (RIPI). Table 1 dipicts physical propertis of CSWCNTs.<smiles>C[CH]O[PH2+]OC(=O)[18C]C(C)=O</smiles>

Figure 1: Chemical structure of PEBAX 3000.

A $2.6 w t \%$ polymer solution was prepared by dissolving $0.26 \mathrm{~g}$ PEBAX in $9.74 \mathrm{~g}$ DMAc under reflux $\left(90^{\circ} \mathrm{C}\right)$, and the solution was stirred for $3 \mathrm{~h}$. In the next step, solution was poured into a petri dish placed on a flat hot-stage at $60-70^{\circ} \mathrm{C}$ in order to form a film at the bottom of petri dish. After about $90 \mathrm{~min}$, solvent completely evaporated and some distilled-water was subsequently poured into the petri dish and polymeric film was then separated from glass, and dried at room temperature. To ensure that no solvent remains within polymer matrix, fabricated membranes were placed in a vacuum oven at $90^{\circ} \mathrm{C}$ for $18 \mathrm{~h}$. For preparation of MMMs, the appropriate amount of CSWCNTs nanofillers were first dispersed in $9.74 \mathrm{~g}$ DMAc and then placed in an ultrasonic apparatus for $1 \mathrm{~h}$ to ensure that nanofillers were properly dispersed throughout the solvent. The suspension was last added to provided PEBAX solution, and composite membranes were fabricated using casting solution.

\subsection{Membrane Characterization}

\subsubsection{Surface Morphology}

Surface morphology of both pristine PEBAX membranes and MMMs were studied using AFM and SEM images. The AFM images were obtained using universal scanning probe microscope (SPM) analyzer, Solver P-47H AFM (NT-MDT, Russia). Moreover, elemental analysis and mapping of nanofillers distribution within polymer matrix were investigated employing SEM-EDX spectrometer. Cross-section morphology of the MMMs (consisting 10wt\% CSWCNTs) was obtianed using field emission scanning electron microscopy (FESEM) MIRA TESCA model at voltage of $15 \mathrm{kV}$.

Table 1: Physical Properties of Carboxylated Single Wall Carbon Nanotube

\begin{tabular}{|c|c|c|c|c|c|}
\hline Length & $\begin{array}{c}\text { Outer } \\
\text { diameter }\end{array}$ & $\begin{array}{l}\text { Inside } \\
\text { diameter }\end{array}$ & $\begin{array}{c}\text { Bulk } \\
\text { density }\left(\mathrm{g} / \mathrm{cm}^{3}\right)\end{array}$ & True density $\left(\mathrm{g} / \mathrm{cm}^{3}\right)$ & $\begin{array}{c}\text { Specific surface } \\
\text { area }\left(\mathrm{m}^{2} / \mathrm{g}\right)\end{array}$ \\
\hline $30 \mathrm{~nm}$ & $1-2 n m$ & $0.8-1.6 \mathrm{~nm}$ & 0.14 & $\sim 2.1$ & 407 \\
\hline
\end{tabular}




\subsubsection{Thermal Characterestics}

The thermal properties of samples were investigated using a differencial scanning calorimetry (Perkin-Elmer DSC-7), from $30^{\circ} \mathrm{C}$ up to $250{ }^{\circ} \mathrm{C}$ at the heating rate of $20^{\circ} \mathrm{C} / \mathrm{min}$ under nitrogen purge. The crystallinity degree $\left(X_{c}\right)$ of the membranes were determined using the following equation,

$\mathrm{X}_{\mathrm{c}}(\%)=\left(\Delta \mathrm{H}_{\mathrm{f}} / \Delta \mathrm{H}_{\mathrm{f}}^{0} \times \mathrm{w}\right) \times 100$

Where $\Delta \mathrm{H}_{\mathrm{f}}$ is the fusion enthalpy at the $\mathrm{T}_{\mathrm{m}}$ and $\Delta \mathrm{H}_{\mathrm{f}}{ }^{0}$ is the fusion enthalpy of the $100 \%$ crystalline polymer $\left(\Delta \mathrm{H}_{\mathrm{f}}{ }^{\mathrm{T}}=246 \mathrm{~J} / \mathrm{g}\right.$ for $\mathrm{PA}_{12}$ and $196.6 \mathrm{~J} / \mathrm{g}$ for PEO), and $\mathrm{w}$ stands for the weight percent of PA and PE phases in the block copolymer Pebax [17]. The thermal stability behaviour for all membranes were examined by a Perkin thermogravimetric analyzer, from $30^{\circ} \mathrm{C}$ to 1000 ${ }^{\circ} \mathrm{C}$ and at the heating rate of $20{ }^{\circ} \mathrm{C} / \mathrm{min}$ rate under nitrogen purge. The weight loss (\%) was recorded as a function of temperature.

\subsubsection{Fourier Transform Infrared Spectroscopy}

To study functional groups of polymer membranes, FTIR instrument ISS-88 Bruker model was employed. The typical IR spectrums were recorded in the range of $400-4000 \mathrm{~cm}^{-1}$.

\subsubsection{Contact Angle Measurments}

The contact angle measurements were applied to characterize the hydrophilic/hydrophobic behaviour of the membranes surface. The contact angle of the samples were measured using a sessile drop method. The static contact angles of water droplets on the upper surface of the samples, varying from $55^{\circ}$ to $90^{\circ}$ for pristine PEBAX membrane and from $40^{\circ}$ to $75^{\circ}$ for MMMs (containing 10wt\% CSWCNTs), as a function of normalized time (60s) were recorded.

\subsubsection{Determination of Density, Volume Fraction, Free Volume, Solubility Parameter, and Flory- Huggins Intraction}

The experimental density of the samples were determined with respect to the standard buoyancy method. All samples were dried in vacuum oven at $30^{\circ} \mathrm{C}$ overnight. The experimental density, $\rho_{f}\left(\mathrm{~g} / \mathrm{cm}^{3}\right)$ of the samples can be determined by the following equation [18],

$\rho_{\mathrm{f}}=\frac{\mathrm{wt}_{\text {air }}}{\mathrm{wt}_{\text {air }}-\mathrm{wt}_{\mathrm{ax}}} \times \rho_{0}$

Where $\rho_{0}$ is the density of the auxilary liquid (hexane), $\mathrm{wt}_{\mathrm{air}}$ is sample weight at room temperature, and $\mathrm{wt}_{\mathrm{ax}}$ is sample weight in the auxiliary liquid. The theoretical density of MMMs determined according to the additive model using the following equation [18],

$\rho_{\mathrm{f}}=\phi_{1} \rho_{1}+\phi_{2} \rho_{2}$

Where $\rho_{1}\left(2.1 \mathrm{~g} / \mathrm{cm}^{3}\right)$ and $\rho_{2}\left(1.02 \mathrm{~g} / \mathrm{cm}^{3}\right)$ are the densities of the CSWCNTs and PEBAX, respectively. $\phi_{1}$ and $\phi_{2}$ also present the volume fraction of the CSWCNTs and PEBAX, respectively. Volume fraction $\left(\phi_{\mathrm{f}}\right)$ of prepared filmes can be calculated using the following equation,

$$
\phi_{\mathrm{f}}=\frac{\mathrm{W}_{\mathrm{f}}}{\mathrm{W}_{\mathrm{f}}+\left(\frac{\rho_{\mathrm{f}}}{\rho_{\mathrm{P}}} \times\left(1-\mathrm{W}_{\mathrm{f}}\right)\right)}
$$

Where $\rho_{\mathrm{P}}$ and $\rho_{\mathrm{f}}$ stand for the densities of the PEBAX and CSWCNTs, respectivly, and $\mathrm{W}_{\mathrm{f}}$ represents the CSWCNTs weight fraction. Free volume of a polymer is defined as the volume which is not occupied by atoms of polymer chains. A polymer with a high content of free volume can affect the diffusion coefficient of membranes, and gas molecules can diffuse through the voids. In the case of semicrystalline polymers, including PEBAX, gas permeation normally occure through the amorphous region of the polymer. The high mobility of the amorphous polyether segments leads to a facile permeability of gases through the PE region [17]. Free volume of membranes can be calculated using the following Bondis group contribution method [17],

$\mathrm{FFV}=\frac{\mathrm{v}-\mathrm{v}_{0}}{\mathrm{~V}}$

Where $V\left(\mathrm{~cm}^{3} / \mathrm{gr}\right)$ is the specific volume of a polymer matrix (can be calculated from density), and $V_{0}$ $\left(\mathrm{cm}^{3} / \mathrm{gr}\right)$ is the van der Waals volume which can be calculated by the group contribution method as outlined in Bondi [19].

It is plainly visible that if two different materials have a similar solubility parameters, they can be fully miscible. Therefore, the solubility parameter plays an important role in the development of stable commercial chemical formulations. It is imperative to assess phase segregation during product synthesis. In 1950, the solubility parameter was first used by Hildebrand and Scott [20]. The Hildebrand solubility parameter of a substance is defined as the square root of the cohesive energy density (CED) at $298 \mathrm{~K}$ for non-polar compounds. The solubility parameter is defined as follows [21], 


$$
\delta=(C E D)^{1 / 2}
$$

$\mathrm{CED}=\left(\frac{\Delta \mathrm{E}_{\mathrm{V}}}{\mathrm{V}}\right)=\left(\frac{\Delta \mathrm{H}_{\mathrm{V}}-\mathrm{RT}}{\mathrm{V}}\right)$

Where $\delta$ is a solubility parameter, $\Delta \mathrm{E}_{\mathrm{V}}$ is molar energy of vaporization, $\Delta \mathrm{H}_{\mathrm{V}}$ is molar heat of vaporization, and $\mathrm{V}$ is molar volume of a pure solvent. The measurment units are, $\left(\mathrm{cal} / \mathrm{cm}^{3}\right)^{1 / 2}=0.4888 \times$ $\mathrm{MPa}^{1 / 2}$ and $\mathrm{MPa}^{1 / 2}=2.0455 \times\left(\mathrm{cal} / \mathrm{cm}^{3}\right)$.

Van der Waals interactions between solvent and polymer chains for a nonpolar system are generally well expressed by Flory-Huggins interaction parameter $\mathrm{X}$, which is expressed by equation below,

$\chi_{12}=\chi_{\mathrm{S}}+\chi_{\mathrm{H}}$

Where $\chi_{\mathrm{S}}$ and $\chi_{\mathrm{H}}$ are the entropic and enthalpic components of polymer-solvent interactions, respectively. The value of empirical factor $\left(\chi_{S}\right)$ generally for a nonpolar system is equal to 0.34 . The relationship between the solubility parameter and the Flory-Huggins interaction parameter can be expressed using the following equation [21],

$\chi_{\mathrm{H}}=\frac{\mathrm{V}_{\mathrm{s}}}{\mathrm{RT}}\left(\delta_{1}-\delta_{2}\right)^{2}$

Where $\mathrm{V}_{\mathrm{s}}$ stands for solvent molar volume, $\mathrm{R}$ refers to ideal gas constant $(8.314 \mathrm{~J} / \mathrm{mol}), \mathrm{T}$ is the absolute temperature, $\delta_{1}$ and $\delta_{2}$ are the solvent and polymer solubility parameter, respectively. Hansen used the following equation with $\alpha=1$ for the calculation of Flory-Huggins intraction parameters,

$\chi_{12}=\alpha \frac{\mathrm{Vs}}{\mathrm{RT}}\left[\left(\delta_{\mathrm{dS}}-\delta_{\mathrm{dP}}\right)^{2}+0.25\left(\delta_{\mathrm{pS}}-\delta_{\mathrm{pP}}\right)^{2}+0.25\left(\delta_{\mathrm{hS}}-\delta_{\mathrm{hP}}\right)^{2}\right]$

A low value of the Flory-Huggins interaction parameter $(\chi<0.5)$ indicates a high intensity of polymer-solvent interactions, and a good solubility of a polymer into a solvent. Given the Hansen solubility parameter, the cohesive energy can be divided into three parts derived from three types of interaction forces, including dispersive forces $\left(E_{d}\right)$, polar forces $\left(E_{p}\right)$, and hydrogen bonding forces $\left(E_{p}\right)$, degining as follows [21],

$E_{c o h}=E_{d}+E_{p}+E_{h}$

The coresponding equation for Hunsen solubility parameters can be calculated as follows, $\delta_{\mathrm{t}}^{2}=\delta_{\mathrm{d}}^{2}+\delta_{\mathrm{p}}^{2}+\delta_{\mathrm{h}}^{2}$

Thus the distance between solubility parameter of PEBAX 3000 and dimethylacetamid can be calculated using the equation below [18],

$\Delta \delta=\left[\left(\delta_{d, p}-\delta_{d, s}\right)^{2}+\left(\delta_{p, p}-\delta_{p, s}\right)^{2}+\left(\delta_{h, p}-\delta_{h, s}\right)^{2}\right]^{1 / 2}$

\subsubsection{Gas Permeation Measurements}

In general, gases can pass throught nonporous membrane by a solution-diffusion mechanism [22],

$P=S \cdot D$

Where $P$ is permeability coefficent, $S$ and $D$ refer to solubility and diffusivity coefficents, respectively. The solubility is a thermodynamic parameter depending on some parameters, including size of a gas molecule, intermolecular intractions between penetrant and polymer, physical properties, and condensibility of sorbed penetrants. Conversely, the diffusivity is a kinetic parameter, and is a measure of how fast a penatrant diffuse through a nonporous membrane. This parameter depends on some parameters, including penetrant geometry, polymer-penetrant intraction, free volume of polymer matrix, and chain flexibilty of polymer. While the increment in penatrant size leads to the enhancement in solubility, it leads to the decrement in diffusivity. The ideal selectivity $(\alpha)$ for gas pairs of $i$ and $\mathrm{j}$ can be determined using the following equation [16],

$\alpha_{i / j}^{*}=\left(\frac{P_{i}}{P_{j}}\right)=\left(\frac{D_{i}}{D_{j}}\right) \times\left(\frac{S_{i}}{S_{j}}\right)$

Where $\mathrm{P}_{\mathrm{i}}$ and $\mathrm{P}_{\mathrm{j}}$ are the permeability coefficients of pure gases $\mathrm{i}$ and j. Permeabilities of $\mathrm{N}_{2}, \mathrm{CO}_{2}$, and $\mathrm{CH}_{4}$ were measured using a membrane gas separation unit which is exhibited in Figure 2. The apparatus consists of a membrnae cell made form stainless steel with the permeation area of $16.3 \mathrm{~cm}^{2}$. In all experiments the feed pressure was set $6 \mathrm{bar}$, and downstream pressure was remained at the atmospheric pressure. All permeation measurements were performed at $25{ }^{\circ} \mathrm{C}$, and results of gas permeation experiments were recorded once a constant permeability was observed. It should be noted that just after permeation measurements, membranes were placed at vacuum oven. The following equation was used to determine the permeability,

$$
\mathrm{P}=\frac{\mathrm{Q} \times 1}{\mathrm{~A} \times\left(\mathrm{p}_{1}-\mathrm{p}_{2}\right)}
$$




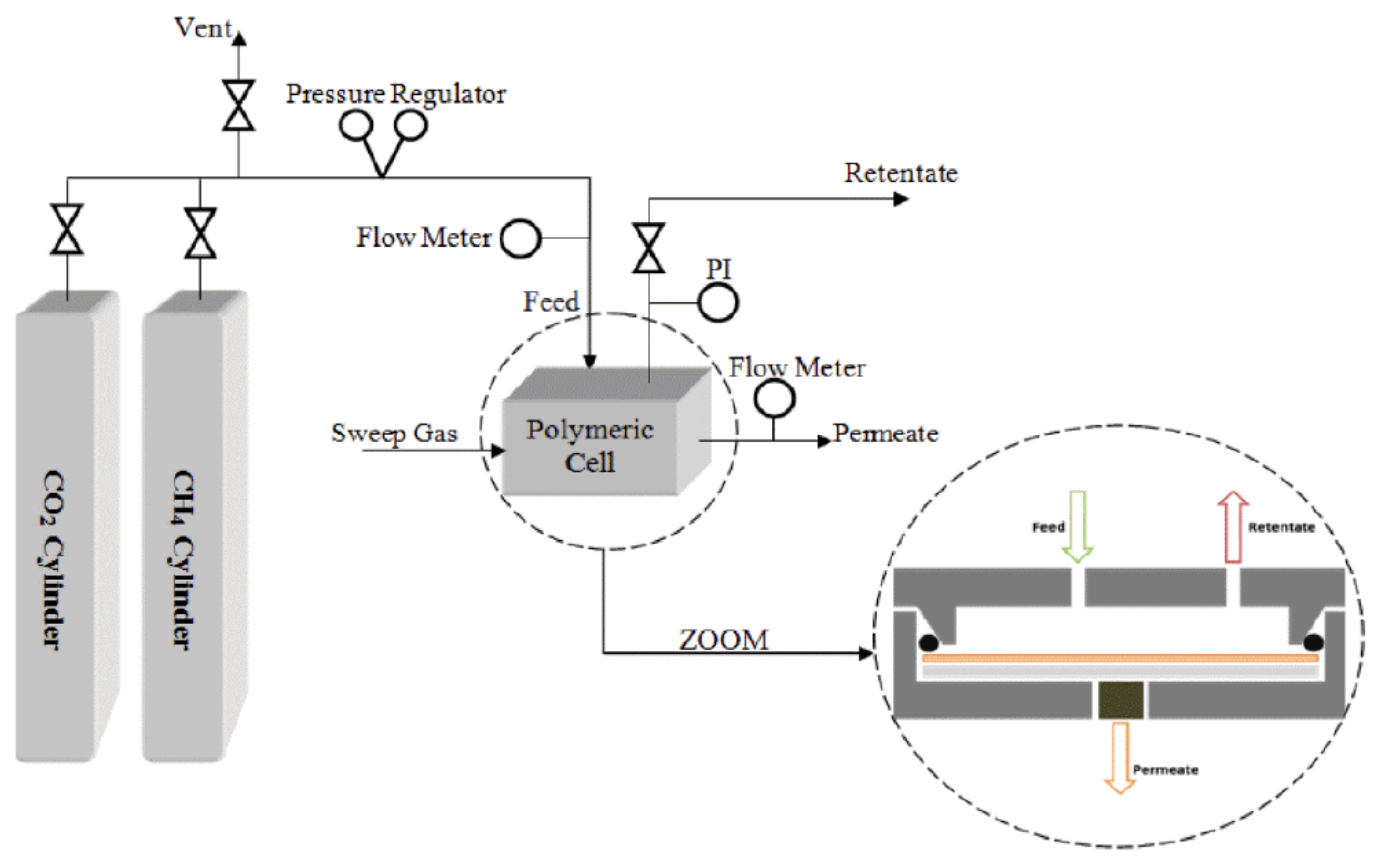

Figure 2: Schematic diagram of gas separation membrnae unit.

Where $P$ is the permeability in barrer ( 1 barrer $=10^{-10}$ $\mathrm{cm}^{3}$ (STP) $\mathrm{cm} / \mathrm{cm}^{2}$.s. $\mathrm{cmHg}$ ), $Q$ is flow rate of the permeate gas $\left(\mathrm{cm}^{3} / \mathrm{s}\right), \mathrm{I}$ is the membrane thickness $(\mathrm{cm}), \mathrm{p}_{1}$ and $\mathrm{p}_{2}$ stand for feed pressure $(\mathrm{cmHg})$ and permeate pressure $(\mathrm{cmHg})$, respectively, and $\mathrm{A}$ is the effective membrane area $\left(\mathrm{cm}^{2}\right)$.

\section{RESULTS AND DISCUSSION}

\subsection{Density and Free Volume Determination}

The additive model revealed that samples densities depend on the characteristics of polymer matrix. Densities of pristine PEBAX membranes and MMMs were determined using buoyancy method. Figure 3 compares experimental and theoretical densities of samples. As can be seen the rise in CSWCNTs content led to the increase in density of MMMs. The value of the experimental density for pristine PEBAX membrnae is $1.02 \mathrm{~g} / \mathrm{cm}^{3}$. It is plainly visible that the values of the experimental densities for all the samples are marginally higher than those of theoretical densities. This is an indication that due to structural compleities all parameters cannot be considered in the theoretical calculations (e.g., inter/intramolecular forces and geometry of cavities) $[17,18]$.

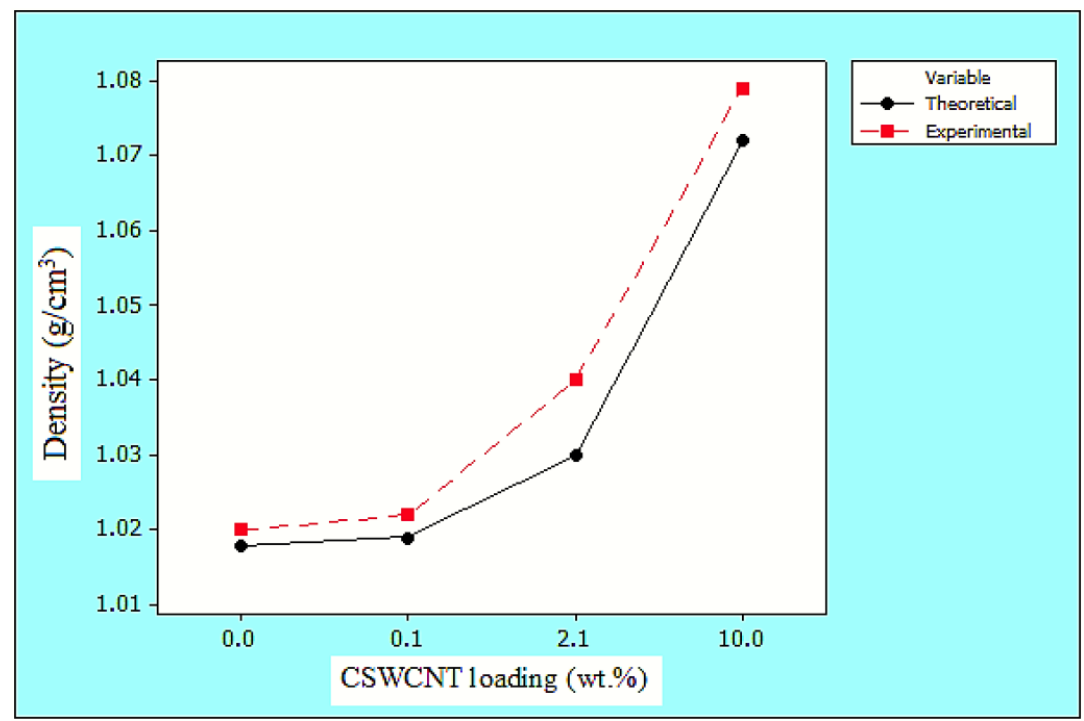

Figure 3: A comparison between theoretical and experimental densities as a function of CSWCNTs loading (wt\%). 


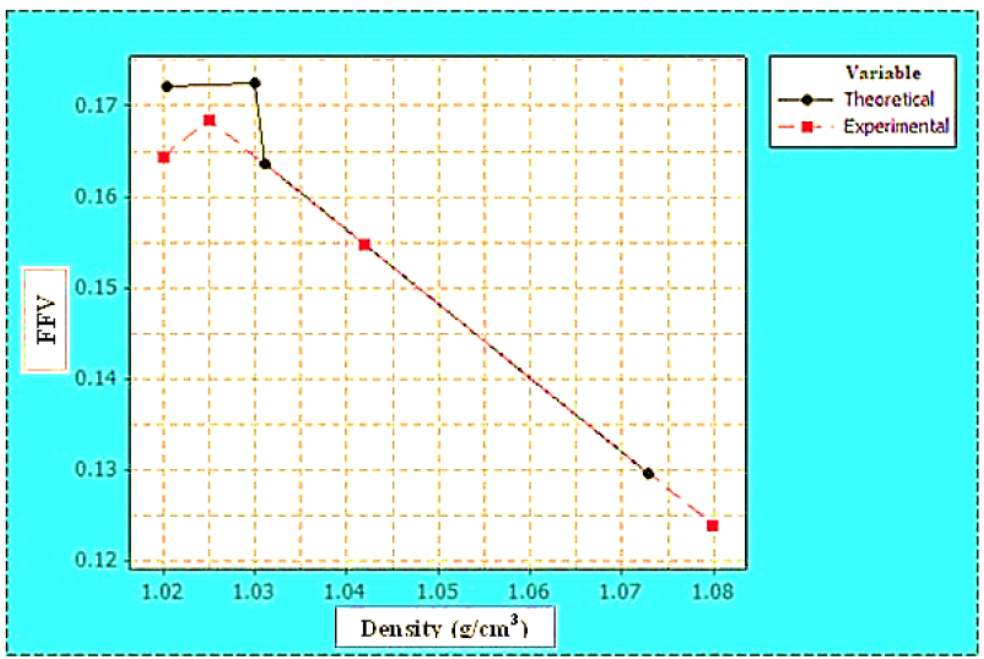

Figure 4: Fractional free volume as a function of theoretical and experimental densities.

Apart from a slight increase in both theoretical and experimental fractional free volume at the very low density values, the rise in densities of samples brought about the decline in both theoretical and experimental fractional free volume (Figure 4).

The increment in figure of CSWCNTs nanofillers $(0.1,2.1$, and $10 \mathrm{wt} \%)$ whitin MMMs can lead to the change in the cavities of PEBAX/CSWCNTs composite membranes. The obtained results can explain the appropriate intractions between the carboxylate groups of CSWCNTs with the functional groups available in PEBAX copolymer, resulting in penetration of the polymer chains inside cylinderical shaped CSWCNTs. The polymer chains can also embrace and surround CSWCNTs. These kinds of interactions can increase the packing density of the prepared membranes. The results of the calculated parameters are presented in Table 2.

\subsection{Solubility Parameter Calculations}

Table 3 represents the calculated parameters required for determination of solubility parameter of PEBAX/solvent and the value of Flory-Huggins interaction. The solubility parameter and Flory-Huggins interaction for PEBAX/NMP are observed to be smaller than those of PEBAX/DMAc. So it can be concluded that PEBAX/NMP gelation is rather faster than PEBAX/DMAc at room temperature. Given PEBAX/Ethanol system, due to the huge differnce between solubility parameters, and large value of FloryHuggins interaction, this solvent seems to be inappropriate for membranes fabrication. PEBAX does

Table 2: Fractional Free Volume Calculations

\begin{tabular}{|c|c|c|c|c|}
\hline $\begin{array}{c}\text { CSWCNTs } \\
\text { loading (wt\%) }\end{array}$ & $\begin{array}{c}\text { CSWCNTs } \\
\text { amount (gr) }\end{array}$ & $\phi_{\mathrm{f}}$ & $\begin{array}{c}\rho \text { additive } \\
\left.\text { (theoretical) (g. } \mathbf{c m}^{-1}\right)\end{array}$ & $\begin{array}{c}\rho \text { experimental } \\
\text { (g. } \mathbf{~ c m}\end{array}$ \\
\hline \hline 0.1 & 0.0260 & 0.000485 & 1.0205 & 1.025 \\
\hline 2.1 & 0.0557 & 0.010314 & 1.0311 & 0.168 \\
\hline 10 & 0.2800 & 0.049706 & 1.073 & 0.154 \\
\hline
\end{tabular}

Table 3: Physical Properties of PEBAX and Various Solvents

\begin{tabular}{|c|c|c|c|c|c|c|c|}
\hline Type & $\boldsymbol{\delta}_{\mathrm{d}}\left(\mathrm{MJ} / \mathrm{m}^{3}\right)^{1 / 2}$ & $\delta_{p}\left(M J / m^{3}\right)^{1 / 2}$ & $\delta_{h}\left(M J / m^{3}\right)^{1 / 2}$ & $\delta_{t}\left(M J / m^{3}\right)^{1 / 2}$ & $\Delta \boldsymbol{\delta}\left(\mathbf{M J} / \mathrm{m}^{3}\right)^{1 / 2}$ & $\mathrm{~V}_{\mathrm{m}}\left(\mathrm{cm}^{3} / \mathrm{mol}\right)$ & $\chi_{12}$ \\
\hline Pebax MV 3000 & 21.23 & 9.38 & 8.43 & 24.69 & & & \\
\hline NMP & 18.0 & 12.3 & 7.2 & 22.95 & 4.52 & 96.5 & 0.32 \\
\hline DMAc & 16.8 & 11.5 & 10.2 & 22.77 & 5.22 & 92.997 & 0.55 \\
\hline Ethanol & 15.8 & 8.8 & 19.4 & 26.52 & 12.25 & 58.5 & 5.36 \\
\hline
\end{tabular}


not dissolve in DMAc at room temperature, and prepared solution is stable only at elevated temperature. Hence the dissolution of PEBAX in DMAc was carried out at elevated temperature under reflux. The low value (0.55) of Flory-Huggins interaction confirms a suitable solubility of PEBAX and DMAC under reflux.

Intraction mechanism between polymer-solvent system can be categorized according to the orthogonal dipolar interactions among dipoles of amide $\mathrm{C}=\mathrm{O}$ bond of carbonyl group $(\mathrm{C}=\mathrm{O} \cdots \mathrm{C}=\mathrm{O})$. Under reflux condition, DMAc (as solvent) can penetrate into the polymer chains, each of which has a helical-space conformation. Hydrogen bonding between polyamide and polyether chains breaks, dissolving of copolymer in the solvent [23]. In accordance with above explanation, DMAc was selected to prepare polymeric solution and other alternatives were eliminated.

\subsection{Thermal Properties of Membranes}

\subsubsection{DSC Analysis}

Table 4 represents data about the thermal properties of the samples measured using DSC thermograms. In Table 4, pristine PEBAX membrane and composite membranes containing $0.1,2.1$, and $10 \mathrm{wt} \%$ CSWCNTs are represented as $\mathrm{PC}_{0}, \mathrm{PC}_{1}, \mathrm{PC}_{2}$, and $\mathrm{PC}_{3}$, respectively. Except for membrane containing $10 \mathrm{wt} \%$ CSWCNTs, the increment in amount of nanofillers in MMMs leads to the rise in melting temperature $\left(T_{m}\right)$ of $P E$ phase. What is more, the increase in $T_{m}$ values of polyether phases of the membranes containing 0.1 and $2.1 \mathrm{wt} \%$ nanofillers brings about the rise in rigidity and re-arrangment of the polyether phase of the polymer matrix. In the case of the membrane loaded by $10 \mathrm{wt} \%$ CSWCNTs, $\mathrm{T}_{\mathrm{m}}$ value declined, indicating high flexibility of polyether chains.

On the other hand, the increment in amount of nanofillers in MMMs caused the fall in $T_{m}$ values of crystalline PA phases. The above results can refer to the formation of the inter/intramolecular bonding between PA phase and CSWCNTs incorporated into the PEBAX matrix, resulting disordered arrangment in crystalline phase, which is responsible for the decline in $\mathrm{T}_{\mathrm{m}}[24,25]$.

Arrangment of the crystalline phase is, in part, distorted by the effect of CSWCNTs within the PA phase. Calculations confirmed that the degree of crystallinity of PE phase rose, when amount of CSWCNTs increased from 0.1 to $2.1 \mathrm{wt} \%$ whereas crystallinity degree in the case of PEBAX/CSWCNTs $10 \mathrm{wt} \%$ dropped to 3.02. The converse trend was observed in the case of PA phase, in other words, the rise in amount of nanofillers posed the decrease to the crystallinity degree of PA phase. It is due to the effect of highly loaded nanofillers whitin polymer matrix. Therefore, incorporation of $10 \mathrm{wt} \%$ CSWCNTs can lead to higher flexibility of PA phase, and can result in creation of new defects in crystal lattice of PA phase. Thus, crystallinity degree of PA phase decreased from $21.22 \%$ to $12.60 \%$. It is worth noting that incorporation of $10 \%$ of nanofillers has a positive effect on permselectivity of MMMs for $\mathrm{CO}_{2} / \mathrm{CH}_{4}$ separation. Figure 5 shows how introducing CSWCNTs to the PEBAX membranes can affect the crystallinity degrees of PE and PA phases [25, 26].

\subsubsection{TGA Analysis}

Thermal resistance of pristin membrnaes and MMMs were investigated using thermogravimetric analysis (Figure 6). Degradation temperatures of pristine PEBAX and composite membranes are just before $400^{\circ} \mathrm{C}$. There are no significant weight losses at temperatures below about $400^{\circ} \mathrm{C}$. Both pristine PEBAX and composite membranes have weight losses $<10 \%$ at temperatures below $400^{\circ} \mathrm{C}$. The main reason for this observation can be referred to the early decomposition of impurities, such as water and low molecular weight polymers within the samples $[1,8,22]$. The main weight loss for all of the samples occurs at the temperatures between $400{ }^{\circ} \mathrm{C}$ and $500{ }^{\circ} \mathrm{C}$. To put it another way, the increment in temperature provides the necessary

Table 4: Thermal Properties and Crystallinity of PEBAX Membranes with Different CSWCNTs Content

\begin{tabular}{|c|c|c|c|c|c|c|c|}
\hline Sample & $\begin{array}{c}\text { CSWCNTs } \\
(\mathbf{w t} \%)\end{array}$ & $\begin{array}{c}\mathrm{T}_{\mathrm{m}}(\mathrm{PE}) \\
\left({ }^{\circ} \mathbf{C}\right)\end{array}$ & $\begin{array}{c}\mathrm{T}_{\mathrm{m}}(\mathrm{PA}) \\
\left({ }^{\circ} \mathbf{C}\right)\end{array}$ & $\begin{array}{c}\Delta \mathbf{H}_{\mathrm{f}}(\mathrm{PE}) \\
\left(\mathbf{J g}^{-1}\right)\end{array}$ & $\begin{array}{c}\Delta \mathbf{H}_{\mathrm{f}}(\mathrm{PA}) \\
\left(\mathbf{J g}^{-1}\right)\end{array}$ & $\begin{array}{c}\mathbf{X}_{\mathrm{c}}(\%) \\
(\mathbf{P E})\end{array}$ & $\begin{array}{c}\mathbf{X}_{\mathrm{c}}(\%) \\
(\mathbf{P A})\end{array}$ \\
\hline \hline $\mathrm{PC}_{0}$ & 0 & 68.416 & 161.333 & 2.365 & 20.798 & 2.00 & 21.22 \\
\hline $\mathrm{PC}_{1}$ & 0.1 & 72.670 & 157.337 & 2.873 & 19.397 & 2.43 & 19.70 \\
\hline $\mathrm{PC}_{2}$ & 2.1 & 80.337 & 157.004 & 3.875 & 15.550 & 3.28 & 15.79 \\
\hline $\mathrm{PC}_{3}$ & 10 & 74.933 & 153.600 & 3.572 & 12.412 & 3.02 & 12.60 \\
\hline
\end{tabular}




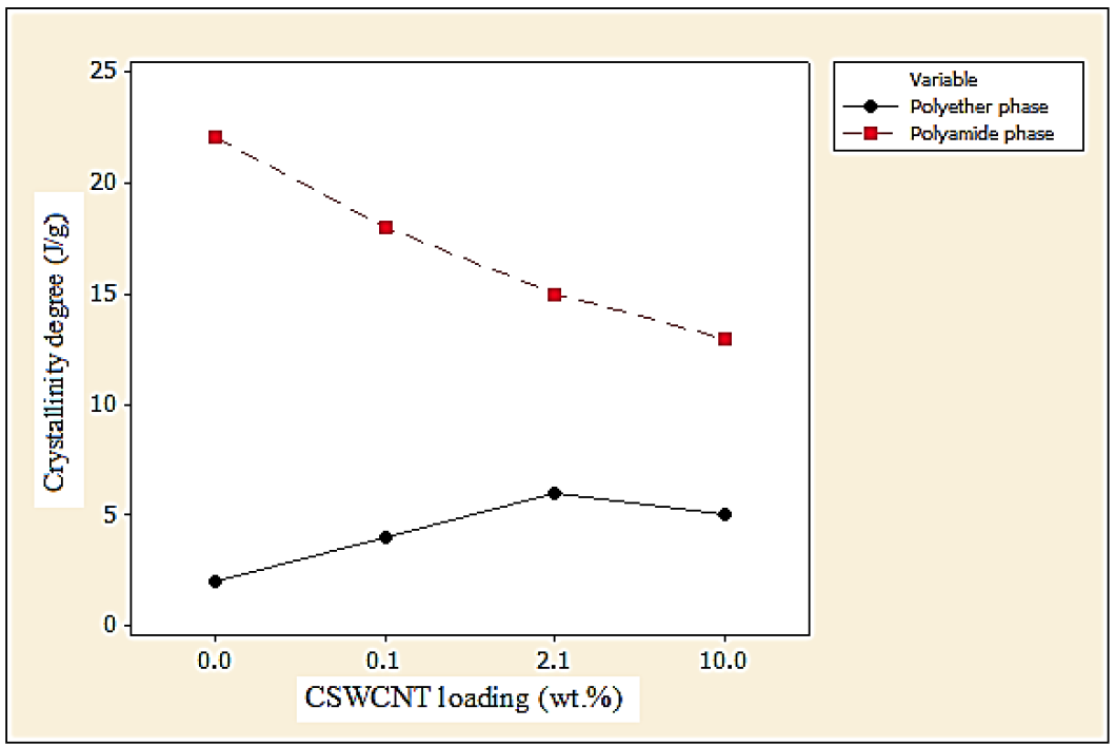

Figure 5: Effect of nanofillers content on crystallinity degree of PE and PA phases.

energy for molecular dissociation of polymer chains. According to the results, approximately similar thermal stabilities of PEBAX membranes are observed.

Regarding Figure 6, it is plainly visible that the rise in figure of nanofillers led to the less weight losses in the last part of thermal degradation curves beginning at $500{ }^{\circ} \mathrm{C}$. It can be attributed to the higher carbon contents in MMMs compairing that of pristine membrane.

\subsection{Contact Angle Measurements}

The changes in contact angle of the pristine PEBAX membrane and MMMs (containing 10\% CSWCNTs) as a function of time are shown in Figure 7. As can be seen, the increment in experiment time, led to the decrease in contact angle of both pristine PEBAX membrane and MMMs, leading to the increase in the relative cohesiveness and intraction of the solid sample with water molecules. The expected increase in the critical surface tension is accompanied with stronger adsorptive behavior [27]. The surface hydrophilicity of MMMs (containing 10wt\% CSWCNTs) is far more that that of pristine PEBAX membrnae. The enhanced surface wettability of the these samples can be attributed to the effect of CSWCNTs loading on the surface polarity of the membranes, and suitable relative cohesiveness of the solid sample with water molecules.

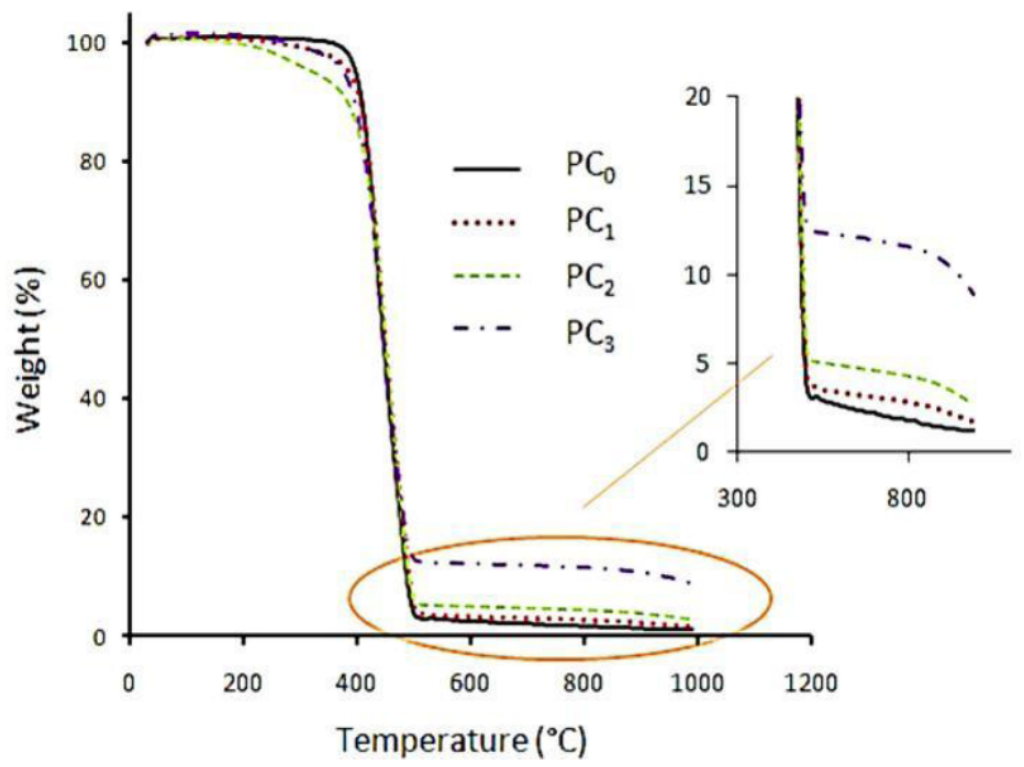

Figure 6: Thermal degradation curves of PEBAX membranes and MMMs. 

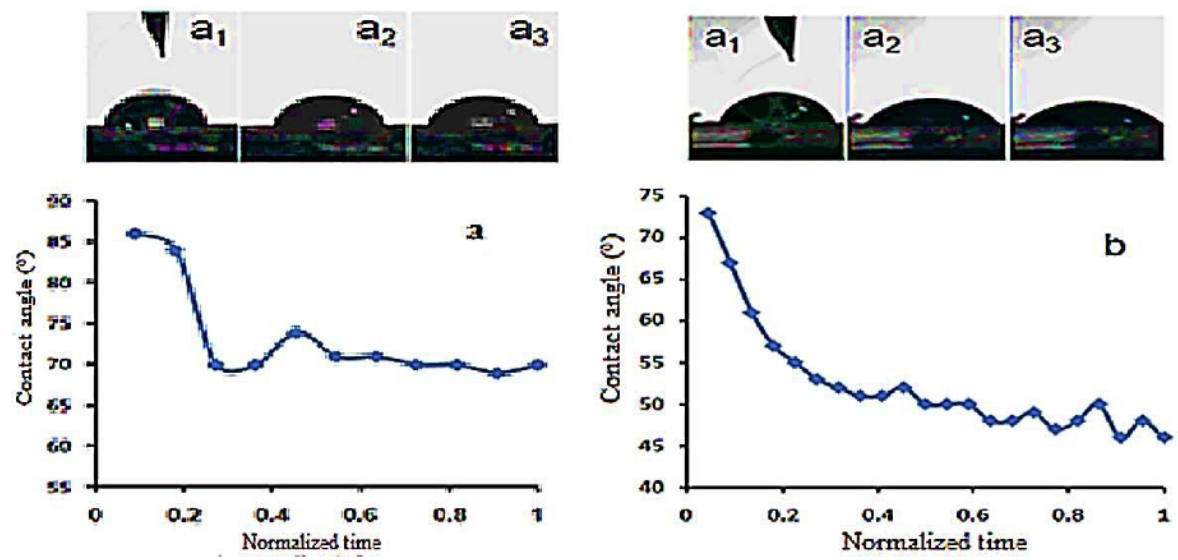

Figure 7: surface contact angle of a) pristine PEBAX membrane and b) MMMs (containing 10wt $\%$ CSWCNTs).

\subsection{FTIR Analysis}

Functional groups and inter/intramolecular interactions were investigeted using FTIR spectroscopy. Figure 8 represents the FTIR spectra of the pristine PEBAX membrane and MMMs (containing 10wt $\%$ CSWCNTs) membranes. In the case of pristine PEBAX membrane, the band at $1110 \mathrm{~cm}^{-1}$ stands for the stretching vibrations of ether groups (C-O-C), and the band appeared at $1564 \mathrm{~cm}^{-1}$ is responsible for the bending vibration of $\mathrm{N}-\mathrm{H}$ group. The band which is responsible for the stretching vibration of carbonyl groups in an amide group $(\mathrm{H}-\mathrm{N}-\mathrm{C}=\mathrm{O})$ appeared at $1641 \mathrm{~cm}^{-1}$ while the stretching vibration of carbonyl group in the state of carbonyl associated with ether oxygen $(\mathrm{O}-\mathrm{C}=\mathrm{O})$ appeared at $1737 \mathrm{~cm}^{-1}$. The absorption frequency of $\mathrm{O}-\mathrm{C}=\mathrm{O}$ group compared to that of $\mathrm{H}-\mathrm{N}-\mathrm{C}=\mathrm{O}$ group is higher, it can be attributed to the higher electron-withdrawing effect (inductive effect) of $\mathrm{O}-\mathrm{C}=\mathrm{O}$ than that of $\mathrm{H}-\mathrm{N}-\mathrm{C}=\mathrm{O}$. In fact, the higher electron-withdrawing property of oxygen atoms in comparison with that of nitrogen atoms led to the stronger bonds and higher force constant $(\mathrm{K})$ of the carbonyl groups in $\mathrm{O}-\mathrm{C}=\mathrm{O}$ groups compared to those of $\mathrm{H}-\mathrm{N}-\mathrm{C}=\mathrm{O}$ groups [26].

Two bands located at $2852 \mathrm{~cm}^{-1}$ and $2921 \mathrm{~cm}^{-1}$ stand for presence of the aliphatic $\mathrm{C}-\mathrm{H}$ connected to the amide group $(\mathrm{H}-\mathrm{C}-\mathrm{CONH})$, and also the band at $3094 \mathrm{~cm}^{-1}$ is related to the presence of the aliphatic $\mathrm{C}-\mathrm{H}$ connected to the ether group (C-O-C-C-H). The absorption band at $3296 \mathrm{~cm}^{-1}$ corresponds to the $\mathrm{N}-\mathrm{H}$ group. Loading of $10 \mathrm{wt} \%$ nanofillers within polymer matrix caused a decrease in force constent $(\mathrm{K})$. Consequently absorbance bands of $\mathrm{C}-\mathrm{O}-\mathrm{C}, \mathrm{N}-\mathrm{H}$, and $\mathrm{H}-\mathrm{N}-\mathrm{C}=\mathrm{O}$ functional groups shifted to the lower frequencies. These changes can be attributed to the intermolecular hydrogen-bondings between the carboxylic group of SWCNT nanofillers and N-H group of polyamide segments. In fact the crystallinity of hard segments of polyamide was reduced.
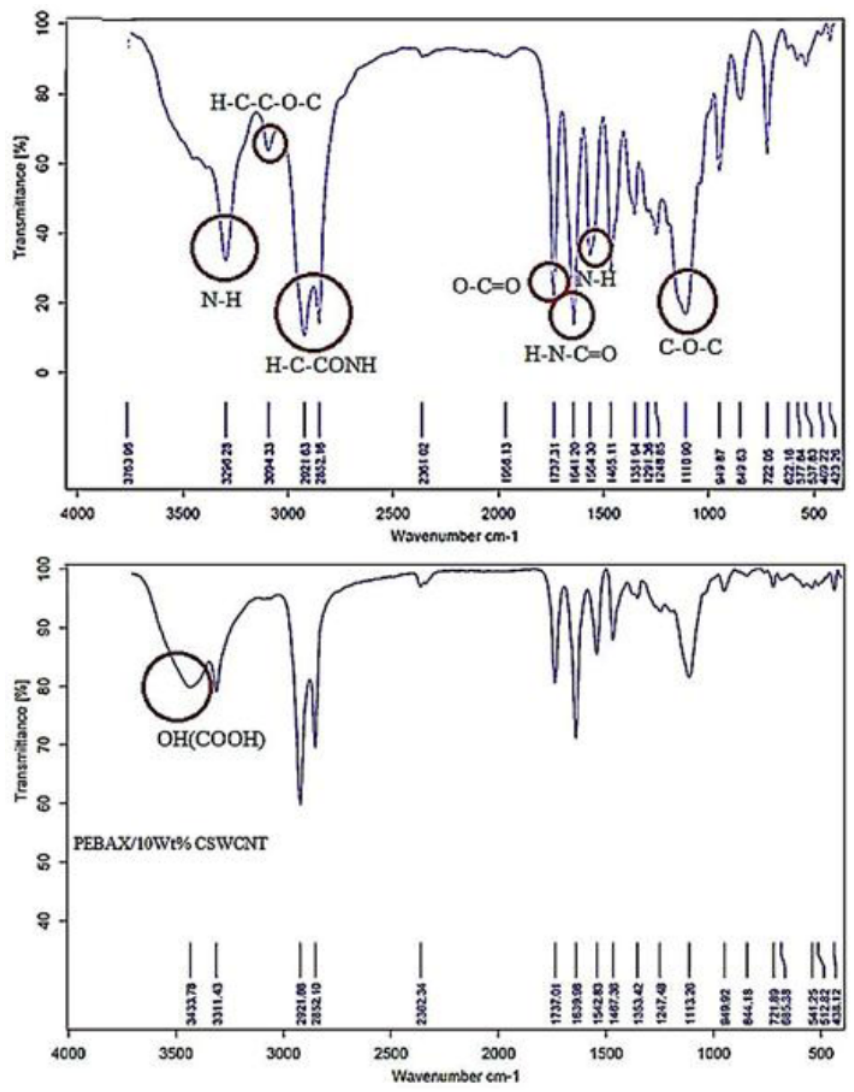

Figure 8: FTIR spectra of pristine PEBAX membrane (upper spectrum), and MMMs containing 10wt\% CSWCNTs (lower spectrum).

Two vibration bands at $3397 \mathrm{~cm}^{-1}$ and $3433 \mathrm{~cm}^{-1}$ stand for the hydrogen-bondings of $\mathrm{OH}$ groups in CSWCNTs nanofillers [28]. Figure 9 demonstrates schematic representation of intermolecular hydrogen bonding between amine group in a PEBAX copolymer and carboxylic group a CSWCNT. 


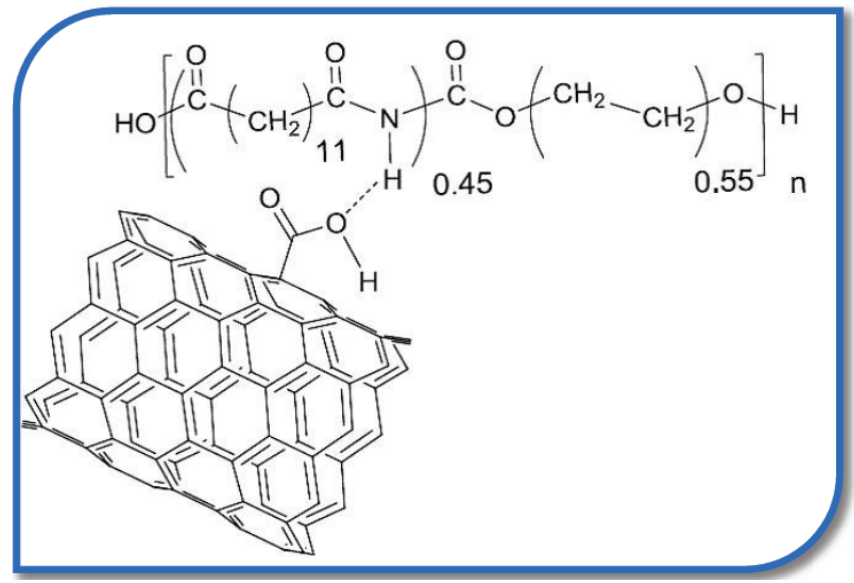

Figure 9: Schematic representation of intermolecular hydrogen bonding between amine group in a PEBAX copolymer and carboxylic group in a CSWCNTs.

\subsection{Morphology Studies of PEBAX Membranes}

Figure 10 depicts pristine PEBAX membranes and two types of MMMs.

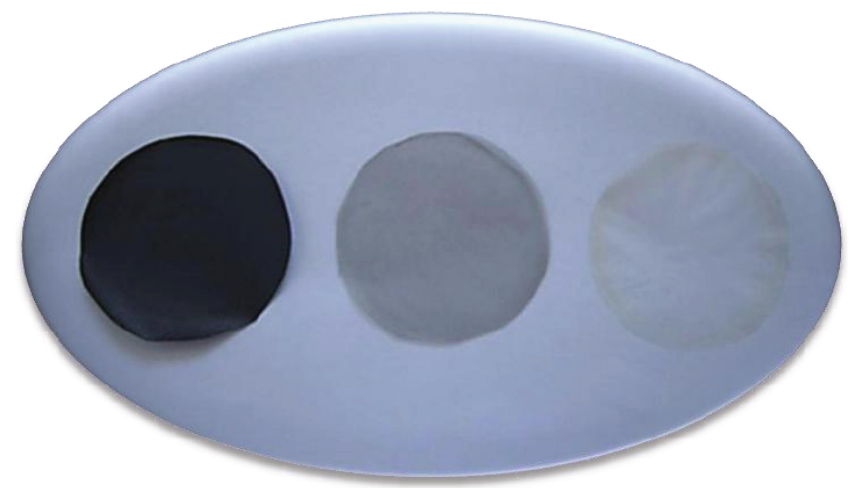

Figure 10: Pristine PEBAX membrane (right), MMMs containing $0.1 \mathrm{wt} \%$ CSWCNTs (middle), and MMMs containing $10 w t \%$ CSWCNTs (left).

\subsubsection{AFM Characterization}

AFM images provide useful information about surface topography, and segments orientation of both polyether and polyamide phases (Figure 11). Regarding Figure 11a, the brighter areas correspons to the PA phase (crystalline regions of PEBAX). The PA phases are surrounded by $P E$ phases (darker areas) [17]. Figure 11b represents the effect of nanofillers on the surface morphology of the MMMs (containing $10 \mathrm{wt} \%$ CSWCNTs). In fact, nanofillers incorporation into polymer matrix led to the formation of closerpacked polymer matrices compared those of pristine PEBAX membranes. The periodic lattices with irregular organization and dark border, which is due to good compatibilty of CSWCNTs with polymer chains, can be observed in Figure 11b [29,30].

\subsubsection{SEM-EDX Characterization}

The cross-section SEM images of MMMs (containnig 10wt $\%$ CSWCNTs) are depicted in Figure 12. These images symbolize a suitable combination and adhesion between PEBAX and CSWCNTs particles. The incorporation of nanofillers into PEBAX matrix results in the formation of microvoids at the polymer-sieves interfaces. Table $\mathbf{5}$ shows the quantitative microanalysis of the pristine PEBAX membranes and MMMs (containing 10wt\% CSWCNTs). The quantitative microanalysis of oxygen and nitrogen atoms clearly indicate the diffusion of CSWCNTs nanofillers within elemental components of the polymer matrix [31].

According to the results indicated in Table 5, while apparent concentration of carbon atoms in pristine PEBAX membranes is 140.21 , it is 118.90 in MMMs (containing $10 \mathrm{wt} \%$ CSWCNTs). To put it another way, incorporation of nanofillers into polymer matrix led to the considerable decrease in apparent concentration of carbon atoms in MMMs. However, the opposite holds true nitrogen and oxygen atoms. When it comes to the intensity ratio of atoms, it is plainly visible that incorporation of CSWCNTs into polymer matrix resulted in the fall in intensity ratio of carbon, whereas intensity ratio of both nitrogen and oxygen atoms increased. When nanofillers were introduced to the pritine PEBAX membranes, weight percent of oxygen atom grew from $13.37 \%$ to $20.27 \%$. Furthermore, the value of atomic percent increased to $16.67 \%$ for the case of oxygen atoms, whereas this value for both carbon and nitrogen atoms decreased.

The microanalysis spectra of both pristine PEBAX membranes and MMMs (containing 10wt \% CSWCNTs) are exhibited in Figure 13. The EDX mapping images of the surface morphology of pristine PEBAX membranes and PEBAX/CSWCNTs (10 wt\%) membranes are represented in Figures 14 and 15, respectively.

As can be clearly observed in Figure 15, nanofillers are distributed finely and randomly throughout the membrane matrix. Given Figures $14 \mathrm{~d}$ and $15 \mathrm{~d}$, the brighter and the darker areas indicate the microphase separation occurred within the polymer matrix, which is a common characteristic of PEBAX copolymer. Whereas the brighter areas corrospond to the PE phase, the darker regions, which are randomly distributed in polymer matrix, stand for the crystalline PA phase [31]. 


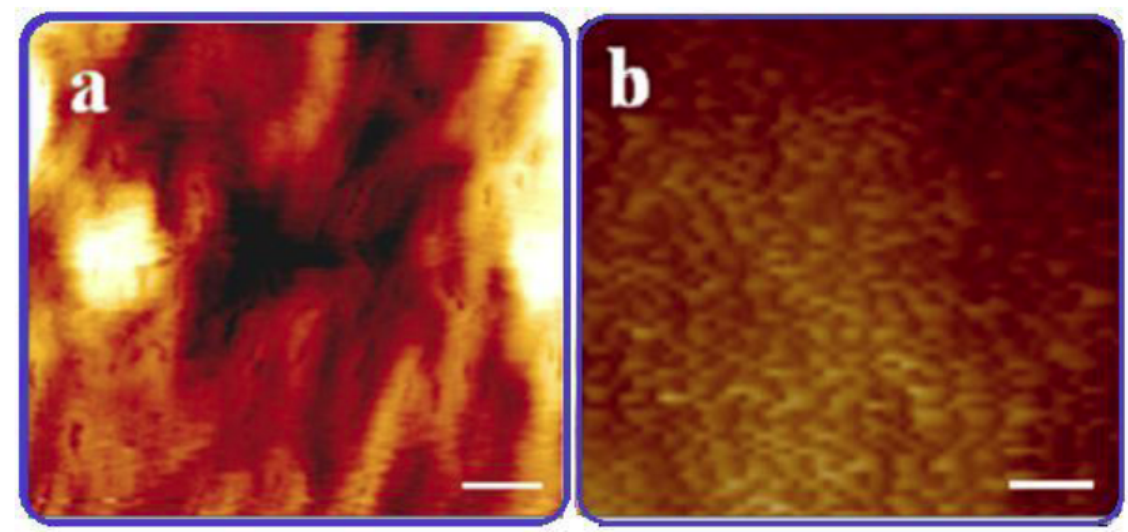

Figure 11: AFM images from surface of membranes a) pristine PEBAX membrane, and b) MMMs containing 10wt\% CSWCNTs (All scale bars represent $10 \mathrm{~nm}$ ).
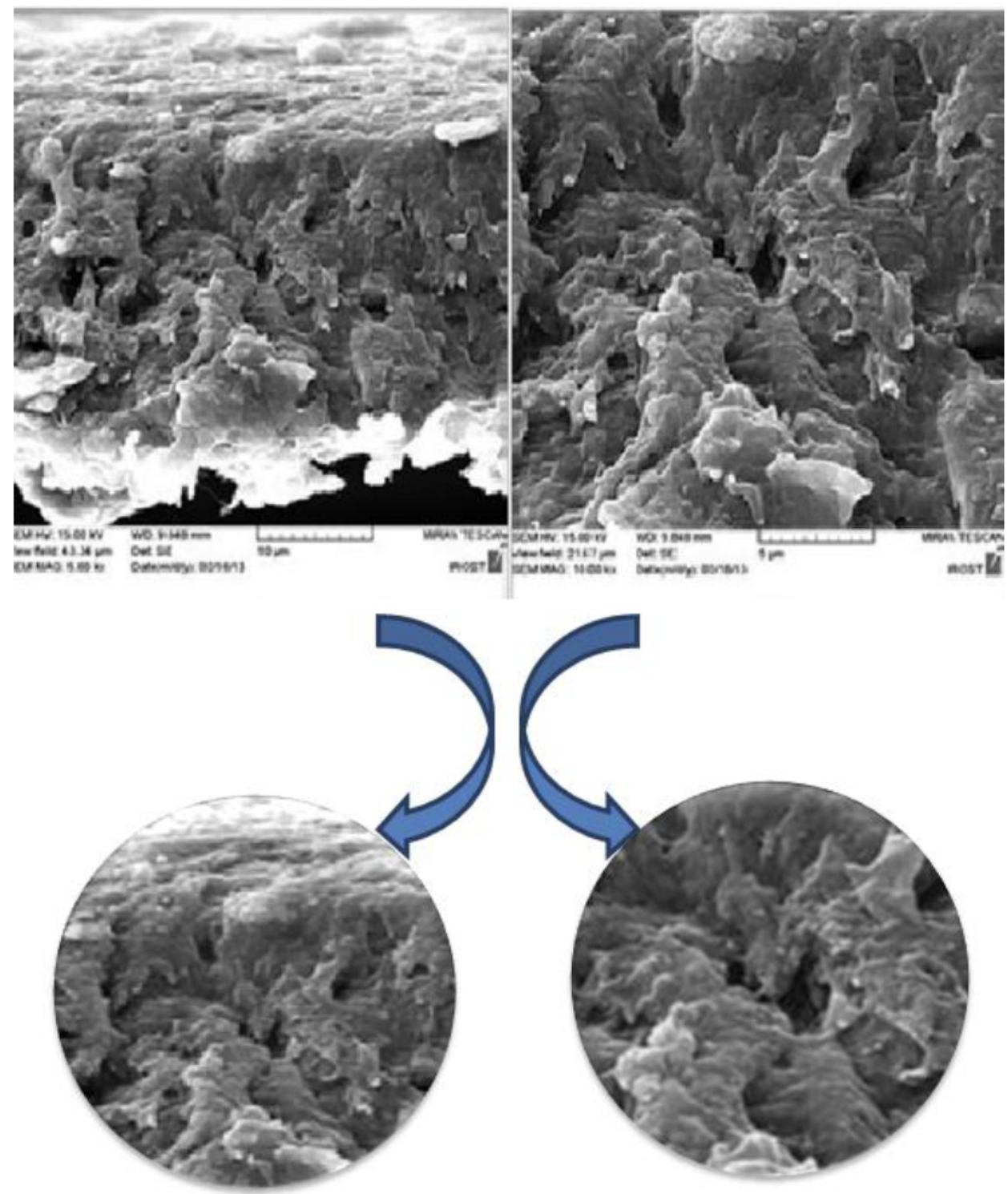

Figure 12: Cross-section SEM images of MMMs (containing 10wt\% CSWCNTs). 
Table 5: Quantitative Elemental Analysis of Upper Surface of Pristine PEBAX Membrane and MMMs (Containing $10 \mathrm{wt} \%$ CSWCNTs)

\begin{tabular}{|c|c|c|c|c|c|c|}
\hline Type & Element & App Conc. & Intensity Corrn. & Weight $\%$ & Weight $\%$ Sigma & Atomic $\%$ \\
\hline \multirow{3}{*}{$\begin{array}{c}\text { Pristine } \\
\text { PEBAX } \\
\text { membrnaes }\end{array}$} & $\mathrm{N} \mathrm{Ka}$ & 3.66 & 0.0928 & 27.02 & 4.17 & 24.96 \\
\hline & $\mathrm{O} \mathrm{Ka}$ & 5.86 & 0.3002 & 13.37 & 1.23 & 10.81 \\
\hline & Total & & & 100.00 & 100.00 & \\
\hline \multirow{3}{*}{$\begin{array}{c}\text { MMMs } \\
\text { (containing } \\
10 w t \% \\
\text { CSWCNTs) }\end{array}$} & $\mathrm{C} \mathrm{Ka}$ & 118.90 & 1.5047 & 53.87 & 2.21 & 59.03 \\
\hline & $\mathrm{O} \mathrm{Ka}$ & 9.79 & 0.3292 & 20.27 & 1.04 & 16.67 \\
\hline & Total & & & 100.00 & 100.00 & \\
\hline
\end{tabular}

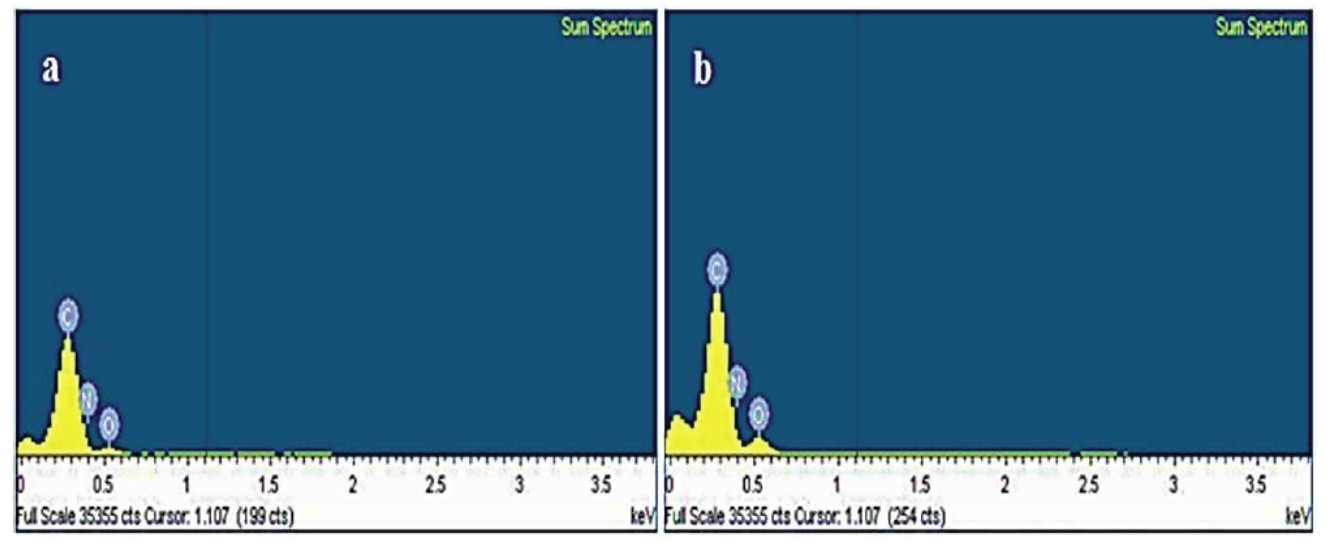

Figure 13: Histogram of intensity versus voltage, a) pristine PEBAX membranes, b) MMMs (containing $10 w t \%$ CSWCNTs).

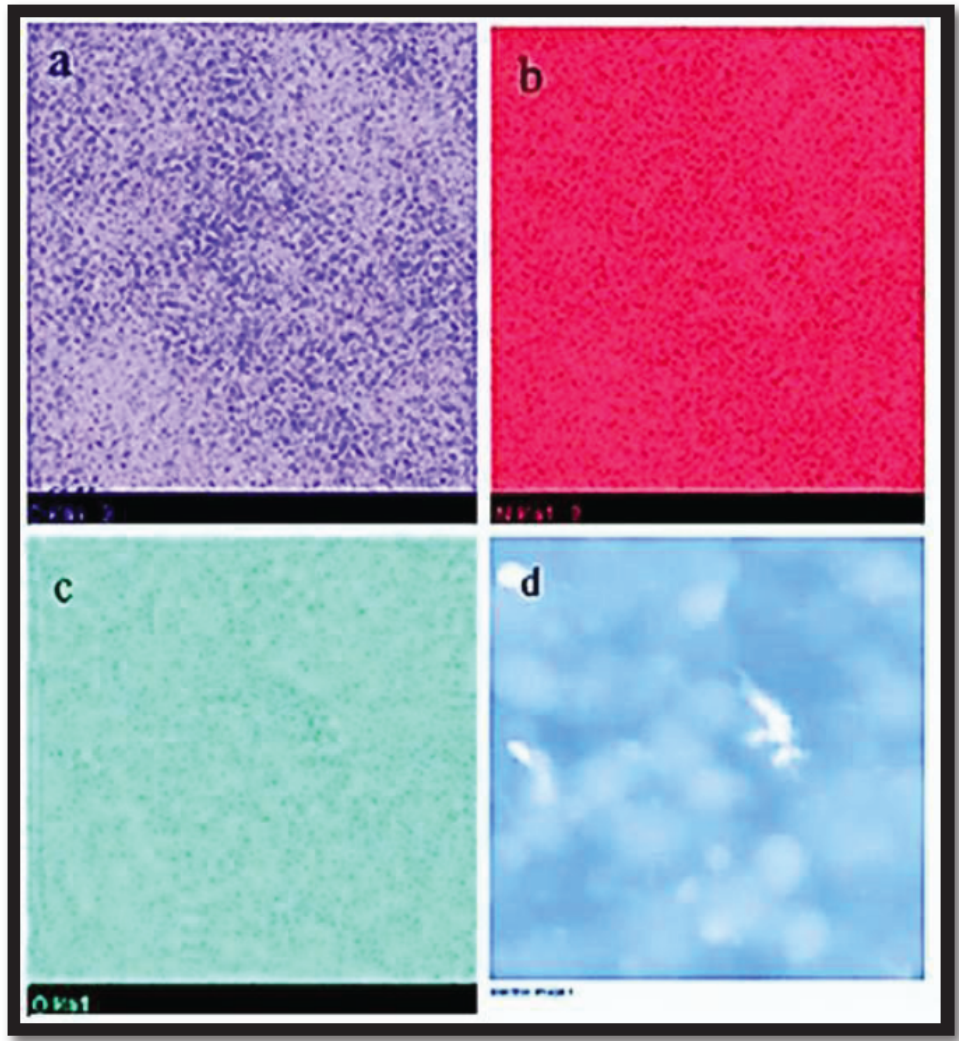

Figure 14: EDX-SEM mapping images of pristine PEBAX membranes. a, b, and c) representative of carbon Ka1, nitrogen Ka1, and oxygen Ka1, respectively, and d) electron image. 


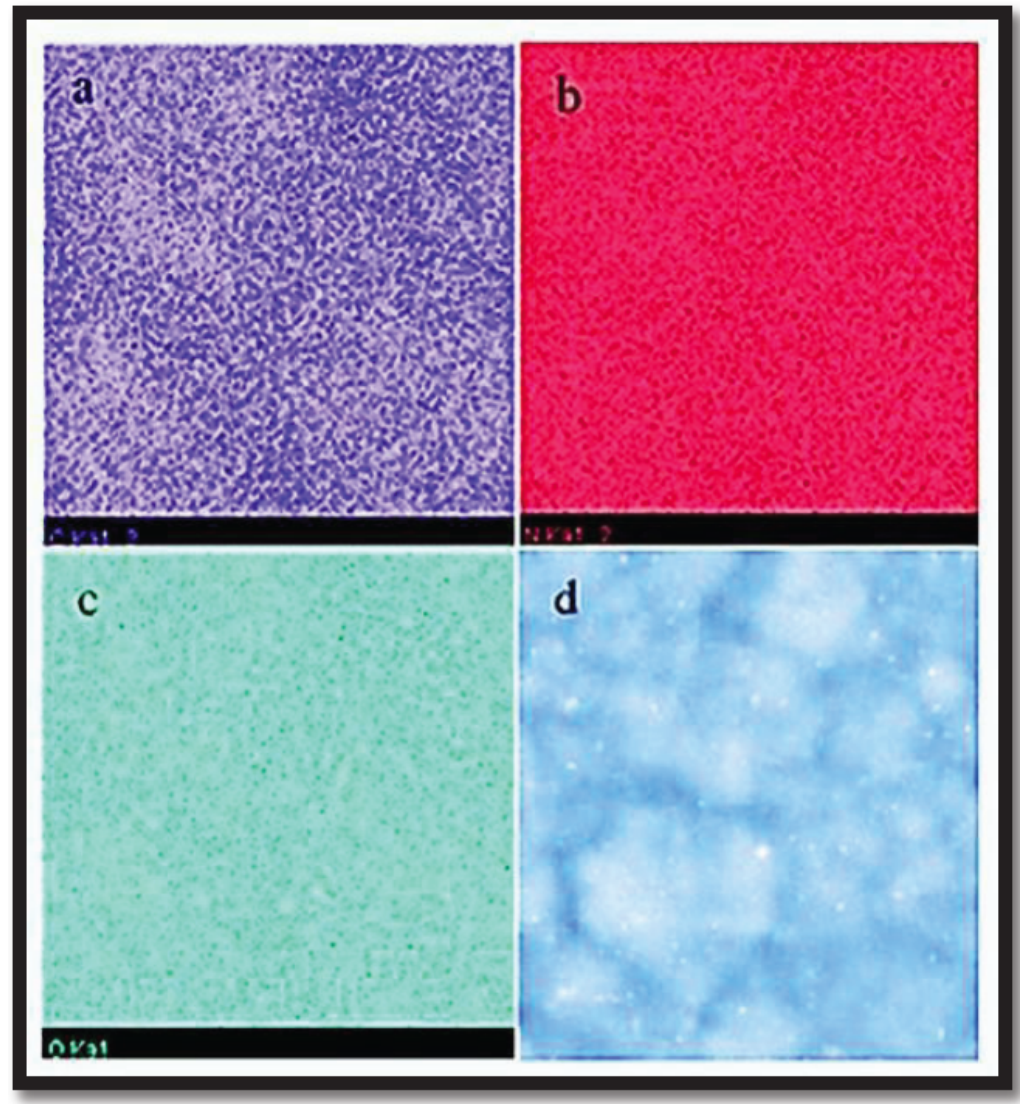

Figure 15: EDX- SEM mapping images of MMMs (containing 10wt\% CSWCNTs). a, b, and c) representative of carbon Ka1, nitrogen $\mathrm{Ka1}$, and oxygen Ka1, respectively, and d) electron image.

\subsection{Effect of CSWCNTs Loading on Permselectivity of PEBAX Membranes}

PEBAX membranes filled with CSWCNTs show an improved selectivity of both $\mathrm{CO}_{2} / \mathrm{N}_{2}$ and $\mathrm{CO}_{2} / \mathrm{CH}_{4}$. Since PEBAX copolymer is consist of immiscible parts, this block copolymer is known for indication of microphase-separated structures [13]. The PA segment provides a mechanical stability for the film whereas the PE segment due to the its mobility, provides sites for the film through which gases can permeate [14]. PEBAX membranes have particularly a high gas separation capability, an illustration for that is separation of $\mathrm{CO}_{2}$ from $\mathrm{N}_{2}$ or $\mathrm{CH}_{4}$. It has been reported that the high $\mathrm{CO}_{2} / \mathrm{N}_{2}$ selectivity can be referred to the high solubility of $\mathrm{CO}_{2}$, which is a highly polarizable gas [32].

PEBAX membranes indicate a nonpolar/polarizablebased gas separation property, making these class of membranes applicable for separation of polarizable gases, such as $\mathrm{CO}_{2}$ and $\mathrm{H}_{2} \mathrm{~S}$ from nonpolar gases $\left(\mathrm{N}_{2}\right.$ and $\mathrm{CH}_{4}$ ). As shown in Figure 16, the increment in polar carboxyl functionalities within PEBAX matrix by adding CSWCNTs to polymer matrix, can give the interactions between $\mathrm{PE}$ blocks of the polymer nanocomposite and $\mathrm{CO}_{2}$ gas a boost $[15,16]$. Hence, introducing CSWCNTs to pristine PEBAX membranes let to the growth in $\mathrm{CO}_{2}$ permeability. Nonpolar gases $\left(\mathrm{N}_{2}\right.$ or $\left.\mathrm{CH}_{4}\right)$, on the other hand, could not interact with polarized site of MMMs, that is all the more reason why the permeability of nonpolar gases through MMMs undergone a decrement. The steric correlations between carboxyl groups of nanofillers and $-\mathrm{C}=\mathrm{O},-\mathrm{N}-$ $\mathrm{H}$, and -O-C-C-O- groups in PEBAX chains can also make an improvemment in permeability of $\mathrm{CO}_{2}$.

Higher $\mathrm{CO}_{2} / \mathrm{N}_{2}$ and $\mathrm{CO}_{2} / \mathrm{CH}_{4}$ selectivity values can be obtained by increasing the CSWCNTs content (see Figure 17). Nanofillers possessing polar groups can affect the solubility selectivity of polar gases. As a matter of fact, incorporation of CSWCNTs into the polymer matrix led to the increase in permeability of $\mathrm{CO}_{2}$, due to the polar nature of CSWCNTs. The increase in ideal selectivity can be explained by the effect of nanofillers on the solubility and diffusivity coefficients. In the case of diffusivity coefficient, the increase in the proportion of nanofillers within polymer matrix posed the decline in FFV of MMMs, causing the drop in diffusivity coefficient for $\mathrm{CO}_{2}, \mathrm{~N}_{2}, \mathrm{CH}_{4}$ [33]. 


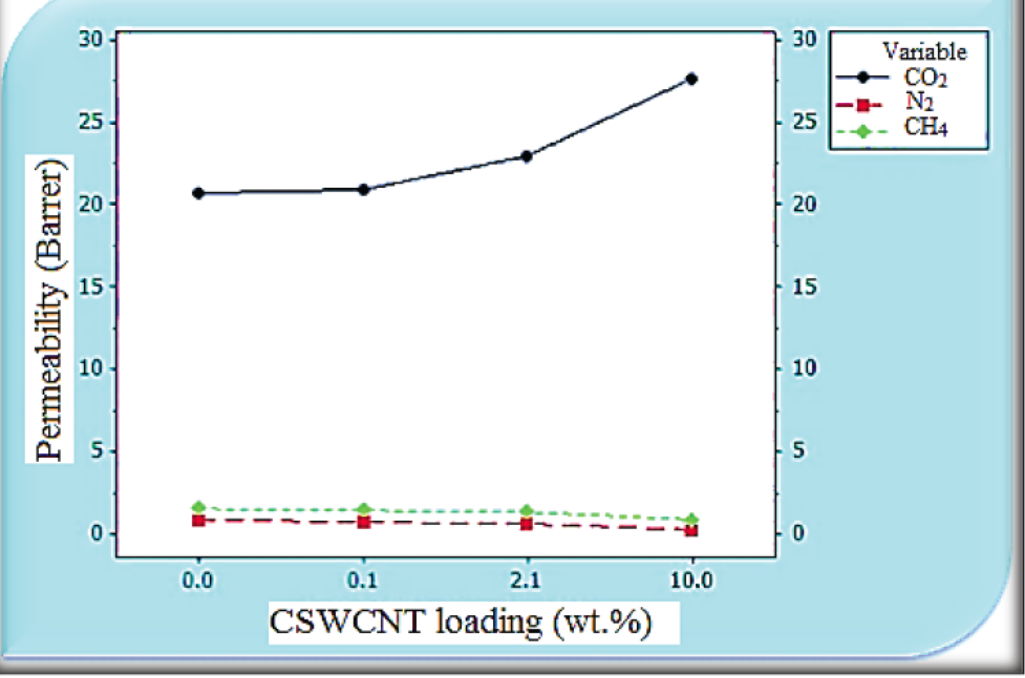

Figure 16: The effect of CSWCNTs loading on permeability properties of $\mathrm{CO}_{2}, \mathrm{CH}_{4}$, and $\mathrm{N}_{2}$ gases (feed pressure of 6 bar).

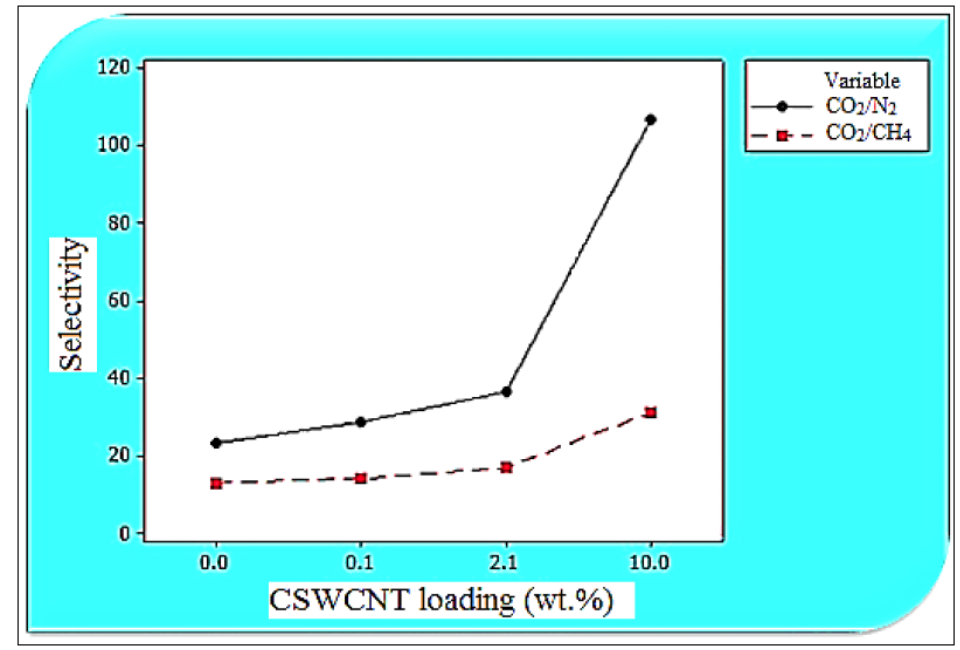

Figure 17: Ideal selectivity of MMMs as a function of nanofillers loading.

MMMs with higher proportion of polar groups exhibited an increase in $\mathrm{CO}_{2}$ solubility coefficient whereas this parameter for $\mathrm{N}_{2}$ and $\mathrm{CH}_{4}$ gases decreased compared to that of pristine PEBAX membranes. The higher value of $\mathrm{CO}_{2}$ solubility coefficient can be attributed to the quadrupole moment of $\mathrm{CO}_{2}$, which is way higher than those of $\mathrm{CH}_{4}$ and $\mathrm{N}_{2}$ as non-polar gases [17, 18, 34].

Table 6 represents the permeability results of pristine PEBAX membrane and MMMs (containing 0.1, 2.1 , and $10 \mathrm{wt} \%$ CSWCNTs, represented as $\mathrm{PC}_{0}, \mathrm{PC}_{1}$, $\mathrm{PC}_{2}$, and $\mathrm{PC}_{3}$, respectively). Despite the higher value of quadrupole moment of $\mathrm{N}_{2}$ compared to that of nonpalar $\mathrm{CH}_{4}$ gas, the higher permeability of $\mathrm{CH}_{4}$ can be attributed to its large potential parameter $\left(e / k_{B}=158.5\right.$ K) $[34,35]$. The selectivity results of $\mathrm{CO}_{2} / \mathrm{N}_{2}$ and $\mathrm{CO}_{2} / \mathrm{CH}_{4}$ are also prepsented in Table 6. No remarkable transformations in selectivity were observed, irrespective of MMMs containing 10wt $\%$ CSWCNTs. However, a considerable improvement in selectivity can be distinguished in the case of MMMs containing $10 \mathrm{wt} \% \mathrm{CSWCNTs}$. The ideal selectivity rose from 23.3 to 106.4 for $\mathrm{CO}_{2} / \mathrm{N}_{2}$, and for $\mathrm{CO}_{2} / \mathrm{CH}_{4}$ this factor increased from 13.2 to 31.3 .

\section{CONCLUSION}

In the present study, the effect of CSWCNTs on the $\mathrm{CO}_{2} / \mathrm{N}_{2}$ and $\mathrm{CO}_{2} / \mathrm{CH}_{4}$ selectivities were investigated. PEBAX matrix was modified by incorporating nanofillers into polymer matrix. Nanofillers with polar properties were applied in order to enhance the permeation of $\mathrm{CO}_{2}$ (as a polar gas) versus $\mathrm{CH}_{4}$ and $\mathrm{N}_{2}$ (as non-polar gases). Incorporation of CSWCNTs nanofillers into polymer matrix not only can increase 
Table 6: Gas Permselectivity Datas for PEBAX Membranes Filled with Different CSWCNTs Content

\begin{tabular}{|c|c|c|c|c|c|}
\hline Sample & $\begin{array}{c}\mathbf{P}\left(\mathrm{CO}_{2}\right) \\
\text { (Barrer) }\end{array}$ & $\begin{array}{c}\mathbf{P}\left(\mathbf{N}_{2}\right) \\
(\text { Barrer })\end{array}$ & $\begin{array}{c}\mathbf{P}\left(\mathbf{C H}_{4}\right) \\
(\text { Barrer })\end{array}$ & $\mathbf{\alpha}\left(\mathbf{C O}_{2} / \mathbf{N}_{2}\right)$ & $\mathbf{\alpha}\left(\mathbf{C O}_{2} / \mathbf{C H}_{4}\right)$ \\
\hline \hline $\mathrm{PC}_{0}$ & 39.7 & 1.7 & 3.0 & 23.3 & 13.2 \\
\hline $\mathrm{PC}_{1}$ & 40.1 & 1.4 & 2.8 & 28.6 & 14.3 \\
\hline $\mathrm{PC}_{2}$ & 44.1 & 1.2 & 2.6 & 36.7 & 17.0 \\
\hline $\mathrm{PC}_{3}$ & 53.2 & 0.5 & 1.7 & 106.4 & 31.3 \\
\hline
\end{tabular}

the polarizability, but also can rise the solubility capacity, which is a great approach to attain highly selective membranes for polar/nonpolar gas separation. In other words, Incorporation of polar inorganic nanofillers into the polymer matrix resulted in more solubility of $\mathrm{CO}_{2}$ (as a polar gas), and less solubility of $\mathrm{N}_{2}$ or $\mathrm{CH}_{4}$ (as non-polar gases) in the MMMs.

Nevertheless, introducing nanofillers to the polymer matrix declined FFV values, and gas diffusivity through MMMs dropped accordingly. While permeation of $\mathrm{N}_{2}$ and $\mathrm{CH}_{4}$ dropped by increasing CSWCNTs content in MMMs, $\mathrm{CO}_{2}$ permeation constantly increased, leading to the rise in $\mathrm{CO}_{2} / \mathrm{CH}_{4}$ and $\mathrm{CO}_{2} / \mathrm{N}_{2}$ selectivities. The approach described in this work is an effective method for polar and nonpolar gases separation.

\section{ACKNOWLEDGEMENT}

The authors immensely acknowledge the Research Institute of Petroleum Industry for financial support (Grant No. 22480826). We would last like to pay tribute to those contributing to the present study.

\section{REFERENCES}

[1] Rahmani M, Kazemi A, Talebnia F. Matrimid mixed matrix membranes for enhanced $\mathrm{CO} 2 / \mathrm{CH} 4$ separation. J Polym Eng 2016; 36: 499-511.

https://doi.org/10.1515/polyeng-2015-0176

[2] Azizi N, Mohammadi T, Behbahani RM. Comparison of permeability performance of PEBAX-1074/TiO2, PEBAX1074/SiO2 and PEBAX-1074/AI2O3 nanocomposite membranes for $\mathrm{CO} 2 / \mathrm{CH} 4$ Separation. Chem Eng Res Des 2017; 117: 177-189.

https://doi.org/10.1016/j.cherd.2016.10.018

[3] Jusoh N, Yeong YF, Lau KK, Shariff AM. Enhanced gas separation performance using mixed matrix membranes containing zeolite T and 6FDA-durene polyimide. J Membr Sci 2017; 525: 175-186.

https://doi.org/10.1016/j.memsci.2016.10.044

[4] Martin-Gil V, López A, Hrabanek P, Mallada R, Vankelecom IFJ, Fila V. Study of different titanosilicate (TS-1 and ETS-10) as fillers for Mixed Matrix Membranes for $\mathrm{CO} 2 / \mathrm{CH} 4$ gas separation applications. J Membr Sci 2017; 523: 24-35. https://doi.org/10.1016/j.memsci.2016.09.041

[5] Peng D, Wang S, Tian Z, Wu X, Wu Y, Wu H, Xin Q, Chen J, Cao $X$, Jiang $Z$. Facilitated transport membranes by incorporating graphene nanosheets with high zinc ion loading for enhanced CO2 separation. J Membr Sci 2017; 522: 351362.

https://doi.org/10.1016/j.memsci.2016.09.040

[6] Boroglu MS, Yumru AB. Gas separation performance of 6FDA-DAM-ZIF-11 mixed-matrix membranes for $\mathrm{H} 2 / \mathrm{CH} 4$ and CO2/CH4 separation. Sep Purif Technol 2017; 173: 269-279. https://doi.org/10.1016/j.seppur.2016.09.037

[7] Sun H, Wang T, Xu Y, Gao W, Li P, Niu QJ. Fabrication of polyimide and functionalized multi-walled carbon nanotubes mixed matrix membranes by in-situ polymerization for $\mathrm{CO} 2$ separation. Sep Purif Technol 2017; 177: 327-336. https://doi.org/10.1016/j.seppur.2017.01.015

[8] Rahmani M, Kazemi A, Talebnia F, Gamali PA. Fabrication and characterization of brominated matrimid ${ }^{\circledR} 5218$ membranes for $\mathrm{CO} 2 / \mathrm{CH} 4$ separation: application of response surface methodology (RSM). e-polymers 2016; 6: 481-492. https://doi.org/10.1515/epoly-2016-0140

[9] Hibshman C, Cornelius CJ, Marand E. The gas separation effects of annealing polyimide-organosilicate hybrid membranes. J Membr Sci 2003; 211: 25-40.

https://doi.org/10.1016/S0376-7388(02)00306-X

[10] Suzuki T, Yamada Y. Physical and gas transport properties of novel hyperbranched polyimide-silica hybrid membranes. Polym Bull 2005; 53: 139-146. https://doi.org/10.1007/s00289-004-0322-9

[11] Abbasszadeh Gamali P, Kazemi A, Zadmard R, Jalali Anjareghi M, Rezakhani A, Rahighi R, Madani M. Distinguished discriminatory separation of $\mathrm{CO} 2$ from its methane-containing gas mixture via PEBAX mixed matrix membrane, Chinese Journal of Chemical Engineering, in press.

https://doi.org/10.1016/j.cjche.2017.04.002

[12] Patel NP, Zielinski JM, Samseth J, Spontak RJ. Effects of pressure and nanoparticle functionality on $\mathrm{CO}$-selective nanocomposites derived from crosslinked poly(ethylene glycol). Macromol Chem Phys 2004; 205: 2409-2419. https://doi.org/10.1002/macp.200400356

[13] Liu L, Chakma A, Feng X. A novel method of preparing ultratin poly(ether block amide) membranes. J Membr Sci 2004; 235: 43-52. https://doi.org/10.1016/j.memsci.2003.12.025

[14] Barbi V, Funari SS, Gehrke R, Scharnagl N, Stribeck N SAXS and gas transport in poly(ether-block-polyamide) copolymer membranes. Macromolecules 2003; 36: 749-758. https://doi.org/10.1021/ma0213403

[15] Kim JH, Ha SY, Lee YM. Gas permeation of poly(amide-6bethylene oxide) copolymer. J Membr Sci 2001; 190: 179193.

https://doi.org/10.1016/S0376-7388(01)00444-6

[16] Lin H, Freeman BD. Materials selection guidelines for membranes that remove $\mathrm{CO} 2$ from gas mixtures. J Mol Struct 2005; 739: 57-74. https://doi.org/10.1016/j.molstruc.2004.07.045

[17] Yumpolskii Y, Freeman BD. Membrane gas separation. John Wiley \& Sons 2010. 
[18] Car A, Stropnik C, Yave W, Peinemann K. PEG modified poly(amide- $b$-ethylene oxide) membranes for $\mathrm{CO} 2$ separation. J Mem Sci 2008; 307: 88-95. https://doi.org/10.1016/j.memsci.2007.09.023

[19] Van Krevelen DW. Properties of polymers: their correlation with chemical structure, their numerical estimation and prediction from additive group contributions. 3rd ed. Elsevier: New York, 1990; p. 875.

[20] Hildebrand J, Scott RL. The Solubility of Nonelectrolytes, 3rd ed., Reinhold, New York 1950.

[21] Hansen CM. Hansen solubility parameter, Handbook, second edition, CRC 2007.

[22] Rahmani M, Kazemi A, Talebnia F, Khanbabaei G. Preparation and characterization of cross-likned matrimid membaranes for $\mathrm{CO} 2 / \mathrm{CH} 4$ separation. Polym Sci Ser B 2014; 56: 650-656. https://doi.org/10.1134/S1560090414050108

[23] Dasgupta S, Hammond WB, Goddard WA. Crystal Structures and Properties of Nylon Polymers from Theory. J Am Chem Soc 1996; 118: 12291-12301. https://doi.org/10.1021/ja944125d

[24] Archondouli PS, Kalfoglou NK. Compatibilization and properties of PBT/PU polymeric alloys. Polymer 2001; 42 : 3489-3502. https://doi.org/10.1016/S0032-3861(00)00758-8

[25] Hu CB, Ward RS, Schneider NS. A new criterion of phase separation: the effect of diamine chain extenders on the properties of polyurethane ureas. J Appl Polym Sci 1982; 27: 2167-2177. https://doi.org/10.1002/app.1982.070270627

[26] Mayo SL, Olafson BD, Goddard WA. A Generic Force Field for Molecular Simulations. J Phys Chem 1990; 94: 88978909. https://doi.org/10.1021/j100389a010

[27] Tutak W, Chhowalla M, Sesti F. The chemical and physical characteristics of single-walled carbon nanotube film impact on osteoblastic cell response. Nano Tech 2010; 21: 315102. https://doi.org/10.1088/0957-4484/21/31/315102
[28] Pavia DL, Lampman GM, Kriz GS. Introduction to spectroscopy, Thomson learning 2001.

[29] Magonov SN, Reneker DH. Characterization of polymer surfaces with atomic force microscopy. Annu Rev Mater Sci 1997; $27:$ 175-222

https://doi.org/10.1146/annurev.matsci.27.1.175

[30] Dasgupta S, Hammond WB, Goddard WA. Crystal Structures and Properties of Nylon Polymers from Theory. J Am Chem Soc 1996; 118: 12291-12301. https://doi.org/10.1021/ja944125d

[31] Corneala LM, Mastenb SJ, Daviesb SHR, Tarabarab VV, Byunb S, Baumann MJ. AFM, SEM and EDS characterization of manganese oxide coated ceramic water filtration membranes. J Membr Sci 2010; 360: 292-302. https://doi.org/10.1016/j.memsci.2010.05.026

[32] Bondar VI, Freeman BD, Pinnau I. Gas transport properties of poly(ether-b-amide; segmented block copolymers. J Polym Sci Part B Polym Phys 2000; 38: 2051-2062. https://doi.org/10.1002/10990488(20000801)38:15<2051::AID-POLB100>3.0.CO;2-D

[33] Gomes D, Nunes SP, Peinemann KV. Membranes for gas separation based on poly(1-trimethylsilyl-1-propyne)-silica nanocomposites. J Membr Sci 2005; 246: 13-25. https://doi.org/10.1016/j.memsci.2004.05.015

[34] Li Y, Chung TS. Highly selective sulfonated polyethersulfone (SPES)-basedmembranes with transition metal counterions for hydrogen recovery and nat-ural gas separation. J Membr Sci 2008; 308: 128-135. https://doi.org/10.1016/j.memsci.2007.09.053

[35] Buckingham AD, Disch RL, Dunmur DA. Quadrupole moments of some simple molecules. J Am Chem Soc 1968; 90: 3104-3107. https://doi.org/10.1021/ja01014a023 